Research Article

\title{
Generalized Reich-Ćirić-Rus-Type and Kannan-Type Contractions in Cone $b$-Metric Spaces over Banach Algebras
}

\author{
Yan Han $\mathbb{1 D}^{1}$ and Shaoyuan $\mathrm{Xu} \mathbb{1}^{2}$ \\ ${ }^{1}$ School of Mathematics and Statistics, Zhaotong University, Zhaotong, China \\ ${ }^{2}$ School of Mathematics and Statistics, Hanshan Normal University, Chaozhou, China \\ Correspondence should be addressed to Shaoyuan Xu; xushaoyuan@126.com
}

Received 15 July 2021; Revised 10 August 2021; Accepted 30 August 2021; Published 27 September 2021

Academic Editor: Zoran Mitrovic

Copyright (c) 2021 Yan Han and Shaoyuan Xu. This is an open access article distributed under the Creative Commons Attribution License, which permits unrestricted use, distribution, and reproduction in any medium, provided the original work is properly cited.

\begin{abstract}
In this paper, we firstly introduce the generalized Reich-Ćirić-Rus-type and Kannan-type contractions in cone $b$-metric spaces over Banach algebras and then obtain some fixed point theorems satisfying these generalized contractive conditions, without appealing to the compactness of $X$. Secondly, we prove the existence and uniqueness results for fixed points of asymptotically regular mappings with generalized Lipschitz constants. The continuity of the mappings is deleted or relaxed. At last, we prove that the completeness of cone $b$-metric spaces over Banach algebras is necessary if the generalized Kannan-type contraction has a fixed point in $X$. Our results greatly extend several important results in the literature. Moreover, we present some nontrivial examples to support the new concepts and our fixed point theorems.
\end{abstract}

\section{Introduction and Preliminaries}

It is well known that the fixed point theory is widely applied to almost all fields of quantitative sciences such as computer science, physics, and biology, especially since the famous Banach contraction principle was introduced in 1922 [1]. In 1968, Kannan [2] studied the following meaningful fixed point theorem, which is a generalization of Banach contraction principle.

Theorem 1. Let $(X, d)$ be a complete metric space and let $T: X \longrightarrow X$ be a mapping such that there exists $K<(1 / 2)$ satisfying

$$
d(T x, T y) \leq K\{d(x, T x)+d(y, T y)\},
$$

for all $x, y \in X$. Then $T$ has a unique fixed point $z \in X$ and for each $x \in X$, the iterated sequence $\left\{T^{n} x\right\}$ converges to $z$.

The mapping satisfying the contractive condition is known as Kannan-type contraction mapping, which is highly interesting since the contraction mapping does not need to be continuous. In 1971, Reich [3] further extended the Banach and Kannan fixed point theorems as follows.

Theorem 2. Let $(X, d)$ be a complete metric space and let $T: X \longrightarrow X$ be a mapping such that there exist $a_{1}, a_{2}, a_{3} \geq 0, a_{1}+a_{2}+a_{3}<1$ satisfying

$$
d(T x, T y) \leq a_{1} d(x, T x)+a_{2} d(y, T y)+a_{3} d(x, y),
$$

for all $x, y \in X$. Then $T$ has a unique fixed point $z \in X$ and for each $x \in X$ the iterated sequence $\left\{T^{n} x\right\}$ converges to $z$.

The mapping satisfying (2) was originally called Reichtype contraction mapping. Since the importance of the Reich-type contraction is simultaneously proved by Ćirić [4] and Rus [5], we say that the mapping $T$ is a Reich-Ćirić-Rus-type contraction mapping. Recently, Górnicki [6] proved the following theorems in compact metric spaces.

Theorem 3. Let $(X, d)$ be a compact metric space and let $T: X \longrightarrow X$ be a continuous mapping satisfying 


$$
d(T x, T y)<\frac{1}{2}[d(x, T x)+d(y, T y)]
$$

for all $x, y \in X$ and $x \neq y$. Then $T$ has a unique fixed point $z \in X$ and for each $x \in X$, the iterated sequence $\left\{T^{n} x\right\}$ converges to $z$.

Theorem 4. Let $(X, d)$ be a compact metric space and let $T: X \longrightarrow X$ be a continuous mapping such that there exist $a_{1}, a_{2}, a_{3} \geq 0, a_{1}+a_{2}+a_{3}=1$ satisfying

$$
d(T x, T y)<a_{1} d(x, T x)+a_{2} d(y, T y)+a_{3} d(x, y),
$$

for all $x, y \in X$ and $x \neq y$. Then $T$ has a unique fixed point $z \in X$ and for each $x \in X$, the iterated sequence $\left\{T^{n} x\right\}$ converges to $z$.

Note that the continuity of the mapping and the compactness of the metric space are essential conditions in Theorems 3 and 4. In order to improve these theorems, Garai et al. [7] investigated some meaningful fixed point theorems of Kannan-type contractive mappings in metric spaces by using the notions of bounded compactness, orbital continuity, and $T$-orbital compactness. Afterwards, Haokip and Goswami [8] extended some related results in $b$-metric spaces by using a subadditive altering distance function. In this paper, we further study the fixed point theorems about Kannan-type and Reich-Cirić-Rus-type contractions in a much broader space.

The concept of $b$-metric space was derived from the work of Bakhtin [9] and Czerwik [10]. They gave a weaker condition than the triangular inequality, with the aim of extending Banach contraction principle. Moreover, in general, a $b$-metric is not a continuous function and thus is a generation of metric [11]. Subsequently, Hussian and Shah [12] introduced cone $b$-metric space which extended cone metric space [13] and $b$-metric space. In cone $b$-metric space, the distance between $x$ and $y$ is defined by a vector in an ordered Banach space, instead of the usual real line (see [14]). In 2013, Liu and $\mathrm{Xu}$ [15] introduced the concept of cone metric space over a Banach algebra by replacing Banach spaces with Banach algebras and considering the contractive constants to be vectors. Moreover, in their paper, it is significant to prove the nonequivalence of fixed point results between metric spaces and cone metric spaces over Banach algebras by some valid examples. In a similar way, the notion of cone $b$-metric space over a Banach algebra was defined by Huang and Radenović [16], which is also nonequivalent to $b$-metric space in terms of the existence of the fixed points of contractions with vector-valued coefficients. Since then, the fixed point theory in these abstract spaces is prompted to be investigated by lots of authors; for detail, see [17-19] and references therein.

In this paper, we prove some fixed point theorems about generalized Kannan-type and Reich-Ćirić-Rus-type contractions in cone $b$-metric spaces over Banach algebras by introducing the notions of bounded compactness, $T$-orbital compactness, orbital continuity, orbital completeness, and asymptotic regularity in cone $b$-metric spaces over Banach algebras. The main conclusion improves and extends some important known results in the literature $[1-3,6,7,20,21]$. Moreover, we prove that the completeness of cone $b$-metric spaces over Banach algebras is necessary if the generalized Kannan-type contraction has a fixed point in $X$. Furthermore, there are some examples to present that our new notions and main conclusions are genuine improvements and extensions of the corresponding notions and works in the literature.

First, let us recall some preliminary concepts of Banach algebras and cone $b$-metric spaces.

Let $\mathscr{A}$ be a real Banach algebra; i.e., $\mathscr{A}$ is a real Banach space in which an operation of multiplication is defined, subject to the following properties: for all, $x, y, z \in \mathscr{A}, a \in \mathbb{R}$

(1) $x(y z)=(x y) z$

(2) $x(y+z)=x y+x z$ and $(x+y) z=x z+y z$

(3) $a(x y)=(a x) y=x(a y)$

(4) $\|x y\| \leq\|x\|\|y\|$

In this paper, we shall assume that the Banach algebra $\mathscr{A}$ has a unit (i.e., a multiplicative identity) $e$ such that $e x=$ $x e=x$ for all $x \in \mathscr{A}$. An element $x \in \mathscr{A}$ is said to be invertible if there is an inverse element $y \in \mathscr{A}$ such that $x y=y x=e$. The inverse of $x$ is denoted by $x^{-1}$. For more details, we refer to [22].

A subset $P$ of $\mathscr{A}$ is called a cone if

(i) $P$ is nonempty and closed and $\{\theta, e\} \subset P$, where $\theta$ denotes the zero element of $\mathscr{A}$

(ii) $\alpha P+\beta P \in P$ for all nonnegative real numbers $\alpha, \beta$

(iii) $P^{2}=P P \subset P$

(iv) $P \cap(-P)=\{\theta\}$

For a given cone $P \subset \mathscr{A}$, we can define a partial ordering $\preccurlyeq$ with respect to $P$ by $x \leqslant y$ if and only if $y-x \in P$. We shall write $x<y$ if $x \leqslant y$ and $x \neq y$, while $x \ll y$ will stand for $y-x \in \operatorname{int} P$, where int $P$ denotes the interior of $P$.

A cone $P$ is called normal if there is a number $K>0$ such that for all $x, y \in \mathscr{A}$,

$$
\theta \preccurlyeq x \preccurlyeq y \quad \text { implies }\|x\| \leq K\|y\| .
$$

The least positive number satisfying the above inequality is called the normal constant of $P$. Indeed, the number $K$ cannot be less than 1 ; see [23]. A cone $P$ is called regular if every increasing sequence which is bounded from above is convergent. In other words, if there is a $y \in \mathscr{A}$ such that

$$
x_{1} \preccurlyeq x_{2} \preccurlyeq \cdots \preccurlyeq x_{n} \preccurlyeq \cdots \preccurlyeq y,
$$

then there exists $x \in \mathscr{A}$ such that $\lim _{n \longrightarrow \infty}\left\|x_{n}-x\right\|=0$. Equivalently, a cone $P$ is regular if and only if every decreasing sequence which is bounded from below is convergent. It is well known that every regular cone is normal.

A cone $P$ is called strongly minihedral if each subset of $\mathscr{A}$ which is bounded from above has a supremum. If $P$ is a strongly minihedral cone, then every subset of $\mathscr{A}$ bounded below has an infimum (see [24, 25]).

Throughout this paper, we always assume that $P$ is a cone over Banach algebra $\mathscr{A}$ with $\operatorname{int} P \neq \varnothing$ and $\leqslant$ is the partial ordering with respect to $P$. 
Definition 1 (see $[12,16,17,18]$ ). Let $X$ be a nonempty set and $s \geq 1$ be a constant. Suppose that the mapping $d: X \times$ $X \longrightarrow \mathscr{A}$ satisfies the following:

(d1) $\theta \leqslant d(x, y)$ for all $x, y \in X$ and $d(x, y)=\theta$ if and only if $x=y$

(d2) $d(x, y)=d(y, x)$ for all $x, y \in X$

(d3) $d(x, y) \preccurlyeq s[d(x, z)+d(z, y)]$ for all $x, y, z \in X$

Then $d$ is called a cone $b$-metric on $X$ and $(X, d)$ is called a cone $b$-metric space over Banach algebra $\mathscr{A}$.

Definition 2 (see $[14,16])$. Let $(X, d)$ be a cone $b$-metric space over a Banach algebra $\mathscr{A}, x \in X$ and $\left\{x_{n}\right\}$ a sequence in $X$. Then,

(i) $\left\{x_{n}\right\}$ converges to $x$ if, for every $c \in \mathscr{A}$ with $c \gg \theta$, there is a natural number $N$ such that for all $n>N, d\left(x_{n}, x\right) \ll c$

(ii) $\left\{x_{n}\right\}$ is a Cauchy sequence if, for every $c \in \mathscr{A}$ with $c \gg \theta$, there is a natural number $N$ such that for all $n, m>N, d\left(x_{n}, x_{m}\right) \ll c$ (iii) $(X, d)$ is a complete cone $b$-metric space if every Cauchy sequence is convergent in $X$

It is worth mentioning that unlike the usual metric or cone metric with a normal cone, cone $b$-metric is not necessarily continuous in general even if the cone is normal, as the following example shows.

Example 1. Let $\mathscr{A}=\mathbb{R}^{2}$ with the norm $\left\|\left(x_{1}, x_{2}\right)\right\|=\left|x_{1}\right|+$ $\left|x_{2}\right|$. The multiplication is defined by

$$
x y=\left(x_{1}, x_{2}\right)\left(y_{1}, y_{2}\right)=\left(x_{1} y_{1}, x_{1} y_{2}+x_{2} y_{1}\right) \text {, }
$$

where $x=\left(x_{1}, x_{2}\right), y=\left(y_{1}, y_{2}\right) \in \mathscr{A}$. It follows that $\mathscr{A}$ is a Banach algebra with a unit $e=(1,0)$. Let $P=\left\{\left(x_{1}, x_{2}\right) \in \mathbb{R}^{2}: x_{1}, x_{2} \geq 0\right\}$. Then $P$ is a normal cone with a normal constant $K=1$. Let $X=\mathbb{N} \cup\{\infty\} \times \mathbb{N} \cup\{\infty\}$ for all $x=\left(x_{1}, x_{2}\right), y=\left(y_{1}, y_{2}\right)$. Define the cone $b$-metric $d: X \times$ $X \longrightarrow \mathscr{A}$ by

$$
d\left(\left(x_{1}, x_{2}\right),\left(y_{1}, y_{2}\right)\right)= \begin{cases}(0,0), & x_{1}=y_{1}, x_{2}=y_{2} ; \\ \left(\left|\frac{1}{x_{1}}-\frac{1}{y_{1}}\right|,\left|\frac{1}{x_{2}}-\frac{1}{y_{2}}\right|\right), & \text { one of }\left(x_{1}, x_{2}\right) \text { and }\left(y_{1}, y_{2}\right) \text { is odd and the other is odd or } \infty ; \\ (6,6), & \text { one of }\left(x_{1}, x_{2}\right) \text { and }\left(y_{1}, y_{2}\right) \text { is even and the other is even or } \infty ; \\ (3,3), & \text { otherwise. }\end{cases}
$$

Note that for the definition of the cone $b$-metric $d$ above, $\left(x_{1}, x_{2}\right)$ is odd if both $x_{1}$ and $x_{2}$ are odd; $\left(x_{1}, x_{2}\right)$ is $\infty$ if both $x_{1}$ and $x_{2}$ are $\infty$. Then it is sufficient to check that $(X, d)$ is a cone $b$-metric space over Banach algebra $\mathscr{A}$ with the coefficient $s=2$.

Let $z_{n}=(2 n+1,2 n+3)$ for each $n \in \mathbb{N}$. Then

$$
\begin{aligned}
d\left(z_{n}, \infty\right) & =d((2 n+1,2 n+3),(\infty, \infty)) \\
& =\left(\left|\frac{1}{2 n+1}-\frac{1}{\infty}\right|,\left|\frac{1}{2 n+3}-\frac{1}{\infty}\right|\right) \\
& =\left(\frac{1}{2 n+1}, \frac{1}{2 n+3}\right) \longrightarrow(0,0), \quad(n \longrightarrow \infty) .
\end{aligned}
$$

This gives $z_{n} \longrightarrow \infty$. However,

$$
\begin{aligned}
d\left(z_{n}, 2\right) & =d((2 n+1,2 n+3),(2,2))=(3,3) \nrightarrow(6,6) \\
& =d((\infty, \infty),(2,2))=d(\infty, 2),
\end{aligned}
$$

as $n \longrightarrow \infty$. Therefore, the cone $b$-metric is not continuous even though the cone is normal.
Definition 3 (see [26]). Let $P$ be a solid cone in a Banach algebra $\mathscr{A}$. A sequence $\left\{u_{n}\right\} \subset P$ is a $c$-sequence if for each $c \gg \theta$ there exists $n_{0} \in \mathbb{N}$ such that $u_{n} \ll c$ for $n \geq n_{0}$.

Lemma 1 (see [16]). Let $P$ be a solid cone in a Banach algebra $\mathscr{A}$ and let $\left\{x_{n}\right\}$ and $\left\{y_{n}\right\}$ be sequences in $P$. If $\left\{x_{n}\right\}$ and $\left\{y_{n}\right\}$ are c-sequences and $\alpha, \beta \in P$, then $\left\{\alpha x_{n}+\beta y_{n}\right\}$ is a c-sequence.

Lemma 2 (see [22]). Let $\mathscr{A}$ be a Banach algebra with a unit $e$ and $x \in \mathscr{A}$. If the spectral radius $r(x)$ of $x$ is less than 1 , i.e.,

$$
r(x)=\lim _{n \longrightarrow \infty}\left\|x^{n}\right\|^{1 / n}=\inf _{n \geq 1}\left\|x^{n}\right\|^{1 / n}<1
$$

then $e-x$ is invertible. Actually, $(e-x)^{-1}=\sum_{i=0}^{\infty} x^{i}$.

Inspired by Definition 3 in [24], we introduce a new notion of the distance between a set and a singleton in cone $b$-metric space over a Banach algebra $\mathscr{A}$.

Definition 4. Let $(X, d)$ be a cone $b$-metric space over a Banach algebra $\mathscr{A}$ and $M$ be a nonempty subset of $X$. Let $P$ 
be a normal and strongly minihedral cone. The distance between the set $M$ and the singleton $\{x\}$ is defined as follows:

$$
d(x, M)=\inf \{d(x, y): y \in M\} .
$$

\section{Bounded Compactness and T-Orbital Compactness}

The concepts of bounded compactness and T-orbital compactness were discussed in usual metric spaces [7] and $b$-metric spaces [8], which were important to weaken the condition of compactness. In the following, we give the notions of generalized Kannan-type and Reich-Ćirić-Rustype contractions, bounded compactness, and T-orbital compactness in the framework of cone $b$-metric spaces over Banach algebras, which are generalizations of metric spaces and $b$-metric spaces.

Definition 5. Let $(X, d)$ be a cone $b$-metric space over a Banach algebra $\mathscr{A}$ with a unit $e$. The mapping $T: X \longrightarrow X$ is said to be a generalized Kannan-type contraction, if it satisfies

$$
d(T x, T y) \prec \frac{e}{2}\{d(x, T x)+d(y, T y)\}
$$

for all $x, y \in X$ with $x \neq y$.

Definition 6. Let $(X, d)$ be a cone $b$-metric space over a Banach algebra $\mathscr{A}$ with a unit $e$. The mapping $T: X \longrightarrow X$ is said to be a generalized Reich-Ćirić-Rus-type contraction, if it satisfies

$$
d(T x, T y) \prec a_{1} d(x, T x)+a_{2} d(y, T y)+a_{3} d(x, y),
$$

for all $x, y \in X$ with $x \neq y$, where $a_{1}, a_{2}, a_{3} \in P$ with $a_{1}+a_{2}+a_{3}=e$.

Definition 7. Let $(X, d)$ be a cone $b$-metric space over a Banach algebra $\mathscr{A}$ and $T$ be a self-mapping on $X$. Let $x \in X$ and $O_{T}(x)=\left\{x, T x, T^{2} x, T^{3} x, \ldots\right\}$.

The space $(X, d)$ is said to be boundedly compact, if every bounded sequence in $X$ has a convergent subsequence.

The mapping $T$ is said to be orbitally continuous at a point $z \in X$ if for any sequence $\left\{x_{n}\right\} \subset O_{T}(x)$ (for all $x \in X$ ), $x_{n} \longrightarrow z$ as $n \longrightarrow \infty$ implies $T x_{n} \longrightarrow T z$ as $n \longrightarrow \infty$. Clearly, every continuous mapping is orbitally continuous, but not the converse.

The set $X$ is said to be $T$-orbitally compact set, if every sequence in $O_{T}(x)$ has a convergent subsequence for all $x \in X$.

Example 2. Let $\mathscr{A}=C_{\mathbb{R}}^{1}[0,1] \times C_{\mathbb{R}}^{1}[0,1]$ with the norm

$$
\left\|\left(x_{1}, x_{2}\right)\right\|=\left\|x_{1}\right\|_{\infty}+\left\|x_{2}\right\|_{\infty}+\left\|x_{1}^{\prime}\right\|_{\infty}+\left\|x_{2}^{\prime}\right\|_{\infty} .
$$

Define the multiplication by

$$
x y=\left(x_{1}, x_{2}\right)\left(y_{1}, y_{2}\right)=\left(x_{1} y_{1}, x_{1} y_{2}+x_{2} y_{1}\right) \text {, }
$$

where $x=\left(x_{1}, x_{2}\right), y=\left(y_{1}, y_{2}\right) \in \mathscr{A}$. Then $\mathscr{A}$ is a Banach algebra with a unit $e=(1,0)$. Let $P=\left\{\left(x_{1}(t)\right.\right.$, $\left.\left.x_{2}(t)\right) \in \mathscr{A}: x_{1}(t) \geq 0, x_{2}(t) \geq 0, t \in[0,1]\right\}$.

(1) Let $X=[0, \infty) \times[0, \infty)$ and define the cone $b$-metric $d: X \times X \longrightarrow \mathscr{A}$ by $d\left(\left(x_{1}, x_{2}\right),\left(y_{1}, y_{2}\right)\right)$ $(t)=\left(\left|x_{1}-y_{1}\right|^{2},\left|x_{2}-y_{2}\right|^{2}\right) \cdot \alpha^{t} \in P, \forall x=\left(x_{1}, x_{2}\right)$, $y=\left(y_{1}, y_{2}\right) \in X, \alpha>0$. Then $(X, d)$ is a complete cone $b$-metric space over Banach algebra $\mathscr{A}$ with $s=2$. Define mappings $T_{1}, T_{2}: X \longrightarrow X$ as

for all $x \in X$ and $n \in \mathbb{N}$. This clearly gives that $X$ is $T_{1}$-orbitally compact and boundedly compact but not $T_{2}$-orbitally compact.

(2) Let $X=[0,1) \times[0,1)$. The cone $b$-metric is defined the same as above and $T: X \longrightarrow X$ is defined by $T\left(x_{1}, x_{2}\right)=\left(\left(x_{1} / 2\right),\left(x_{2} / 3\right)\right)$. We deduce that $X$ is $T$-orbitally compact but not complete.

(3) Let $X=[-2,2] \times[-2,2]$. The cone $b$-metric is defined the same as above and $T: X \longrightarrow X$ is defined by

$$
T\left(x_{1}, x_{2}\right)= \begin{cases}(0,0), & \left(x_{1}, x_{2}\right) \in[-1,1] \times[-1,1] ; \\ \left(\frac{x_{1}}{4}, \frac{x_{2}}{6}\right), & \text { otherwise. }\end{cases}
$$

Then, for any $z_{0}=\left(x_{1}, x_{2}\right) \in X, n \in \mathbb{N}, z_{n}=$ $T z_{n-1}, z_{n} \longrightarrow \theta$ implies $T z_{n} \longrightarrow T \theta=\theta(\theta=$ $(0,0))$. So $T$ is orbitally continuous but not continuous in $X$.

In the rest of this section, we always assume that $(X, d)$ is a cone $b$-metric space over Banach algebra $\mathscr{A}$ with regular cone $P$ such that $d(x, y) \in \operatorname{int} P$ for all $x, y \in X$ with $x \neq y$ and the cone $b$-metric $d$ is continuous.

Theorem 5. Let $(X, d)$ be a boundedly compact cone $b$-metric space over Banach algebra $\mathscr{A}$ with a unit $e$ and the coefficient $s \geq 1$. Let $T: X \longrightarrow X$ be a generalized Reich-Cirić-Rus-type contraction mapping and orbitally continuous. If $\left(e-a_{2}\right)^{-1}$ and $\left(e-s^{2} a_{3}\right)^{-1}$ exist, then $T$ has a unique 
fixed point $z \in X$ and for each $x \in X$ the iterated sequence $\left\{T^{n} x\right\}$ converges to $z$; i.e., $T$ is a Picard operator.

Proof. For an arbitrary $x_{0} \in X$, let $x_{n}=T x_{n-1}=T^{n} x_{0}, n \geq 1$. We assume that $x_{n} \neq x_{n+1}$ for all $n \in \mathbb{N}$. Indeed, if for some $n \in \mathbb{N}, x_{n}=x_{n+1}=T x_{n}$, then $x_{n}$ is the fixed point of $T$. Denote $t_{n}=d\left(x_{n}, x_{n+1}\right)$ for each $n \in \mathbb{N}$. By (14), we have

$$
\begin{aligned}
t_{n} & =d\left(x_{n}, x_{n+1}\right)=d\left(T x_{n-1}, T x_{n}\right) \\
& \prec a_{1} d\left(x_{n-1}, x_{n}\right)+a_{2} d\left(x_{n}, x_{n+1}\right)+a_{3} d\left(x_{n-1}, x_{n}\right) \\
& =a_{1} t_{n-1}+a_{2} t_{n}+a_{3} t_{n-1},
\end{aligned}
$$

which gives that $t_{n} \leq\left(e-a_{2}\right)^{-1}\left(a_{1}+a_{3}\right) t_{n-1}$. Let $h=\left(e-a_{2}\right)^{-1}\left(a_{1}+a_{3}\right)$, then $h=e$ by $a_{1}+a_{2}+a_{3}=e$. Therefore, we have

$$
\theta \prec \cdots \prec t_{n} \prec t_{n-1} \prec \cdots \prec t_{0}=d\left(x_{0}, x_{1}\right) .
$$

Because the cone is regular, there exists $b \geqslant \theta$ in $\mathscr{A}$ such that $t_{n} \longrightarrow b(n \longrightarrow \infty)$. Thus, for all $n, m \in \mathbb{N}$, consider

$$
\begin{aligned}
d\left(x_{n}, x_{m}\right) & \leqslant s\left[d\left(x_{n}, x_{n+1}\right)+d\left(x_{n+1}, x_{m}\right)\right] \\
& \preccurlyeq s d\left(x_{n}, x_{n+1}\right)+s^{2} d\left(x_{n+1}, x_{m+1}\right)+s^{2} d\left(x_{m+1}, x_{m}\right) \\
& \prec s d\left(x_{n}, x_{n+1}\right)+s^{2}\left[a_{1} d\left(x_{n}, x_{n+1}\right)+a_{2} d\left(x_{m}, x_{m+1}\right)+a_{3} d\left(x_{n}, x_{m}\right)\right]+s^{2} d\left(x_{m+1}, x_{m}\right) \\
& =\left(s e+s^{2} a_{1}\right) d\left(x_{n}, x_{n+1}\right)+\left(s^{2} a_{2}+s^{2} e\right) d\left(x_{m}, x_{m+1}\right)+s^{2} a_{3} d\left(x_{n}, x_{m}\right),
\end{aligned}
$$

which implies that

$$
\begin{aligned}
d\left(x_{n}, x_{m}\right) \leqslant & \left(e-s^{2} a_{3}\right)^{-1}\left[\left(s e+s^{2} a_{1}\right) d\left(x_{n}, x_{n+1}\right)\right. \\
& \left.+\left(s^{2} e+s^{2} a_{2}\right) d\left(x_{m}, x_{m+1}\right)\right] \\
\prec & \left(e-s^{2} a_{3}\right)^{-1}\left(s e+s^{2} a_{1}+s^{2} e+s^{2} a_{2}\right) t_{0} .
\end{aligned}
$$

Therefore, $\left\{x_{n}\right\}$ is bounded. Since $X$ is boundedly compact, there is a convergent subsequence $\left\{x_{n_{i}}\right\}$ of $\left\{x_{n}\right\}$ and $z \in X$ such that $x_{n_{i}} \longrightarrow z$ as $i \longrightarrow \infty$. So $T x_{n_{i}} \longrightarrow T z$ by the orbital continuity of $T$. If $b>\theta$, then

$$
\theta \prec b=\lim _{i \longrightarrow \infty} d\left(x_{n_{i}}, T x_{n_{i}}\right)=d(z, T z) .
$$

Moreover,

$$
\begin{aligned}
\theta \prec b & =\lim _{i \longrightarrow \infty} t_{n_{i}}=\lim _{i \longrightarrow \infty} d\left(T x_{n_{i}}, T^{2} x_{n_{i}}\right) \\
& =d\left(T z, T^{2} z\right) \prec a_{1} d(z, T z)+a_{2} d\left(T z, T^{2} z\right)+a_{3} d(z, T z),
\end{aligned}
$$

which means

$$
b=d\left(T z, T^{2} z\right) \prec d(z, T z)=b,
$$

a contradiction. Thus, $b=\theta$ and $z=T z$. That is, $z$ is a fixed point of $T$. Then, the inequality (14) implies

$$
\begin{aligned}
d\left(x_{n+1}, z\right) & =d\left(T x_{n}, T z\right) \\
& \prec a_{1} d\left(x_{n}, T x_{n}\right)+a_{2} d(z, T z)+a_{3} d\left(x_{n}, z\right) \\
& =a_{1} d\left(x_{n}, x_{n+1}\right)+a_{3} d\left(x_{n}, z\right) \\
& \preccurlyeq a_{1} d\left(x_{n}, x_{n+1}\right)+a_{3} s^{2}\left[d\left(x_{n}, x_{n+1}\right)+d\left(x_{n+1}, z\right)\right] .
\end{aligned}
$$

Hence, $\quad\left(e-s^{2} a_{3}\right) d\left(x_{n+1}, z\right) \preccurlyeq\left(a_{1}+s^{2} a_{3}\right) d\left(x_{n}, x_{n+1}\right)$ $\longrightarrow \theta$. This gives $T^{n} x \longrightarrow z$; i.e., $T$ is a Picard operator.

Finally, the uniqueness of the fixed point can be obtained by (14). If $y$ is another fixed point of $T$, then

$$
\begin{aligned}
d(y, z) & =d(T y, T z)<a_{1} d(y, T y)+a_{2} d(z, T z)+a_{3} d(y, z) \\
& =a_{3} d(y, z),
\end{aligned}
$$

leading to a contradiction. Therefore, $z$ is the unique fixed point of $T$.

Theorem 6. Let $(X, d)$ be a T-orbitally compact cone $b$-metric space over Banach algebra $\mathscr{A}$ with a unit $e$ and the coefficient $s \geq 1$, where $T: X \longrightarrow X$ is a generalized Reich-Ćirić-Rus-type contraction mapping and orbitally continuous. If $\left(e-a_{2}\right)^{-1}$ and $\left(e-s^{2} a_{3}\right)^{-1}$ exist, then $T$ has a unique fixed point $z \in X$, and for each $x \in X$ the iterated sequence $\left\{T^{n} x\right\}$ converges to $z$; i.e., $T$ is a Picard operator.

Proof. The analysis is similar to that in the proof of Theorem 5. We firstly get the sequence $x_{n}=T x_{n-1}=T^{n} x_{0}, n \geq 1$. If there is an integer $n \in \mathbb{N}$ such that $x_{n}=x_{n+1}=T x_{n}$, then $x_{n}$ is the fixed point. Without loss of generality, we assume that $x_{n} \neq x_{n+1}, \forall n \in \mathbb{N}$. We can prove that $t_{n} \longrightarrow b \geqslant \theta \sim(n \longrightarrow \infty)$, where $t_{n}$ and $b$ are the same as above. As $X$ is $T$-orbitally compact, there is a convergent subsequence $\left\{x_{n_{i}}\right\}$ of $\left\{x_{n}\right\}$ and $z \in X$ such that $x_{n_{i}} \longrightarrow z$ as $n \longrightarrow \infty$. By orbital continuity of $T$, we obtain $T x_{n_{i}} \longrightarrow T z$. The rest proof is similar to Theorem 5 .

Corollary 1. Let $(X, d)$ be a boundedly compact cone $b$-metric space over Banach algebra $\mathscr{A}$ with a unit $e$ and the 
coefficient $s \geq 1$. Let $T: X \longrightarrow X$ be a generalized Kannantype contraction mapping which is orbitally continuous. Then $T$ has a unique fixed point $z \in X$ and for each $x \in X$ the iterated sequence $\left\{T^{n} x\right\}$ converges to $z$; i.e., $T$ is a Picard operator.

Proof. Taking $a_{1}=a_{2}=(e / 2)$ and $a_{3}=\theta$, we obtain the conclusion by Theorem 5 .

Corollary 2. Let $(X, d)$ be a T-orbitally compact cone $b$-metric space over Banach algebra $\mathscr{A}$ with a unit $e$ and the coefficient $s \geq 1$, where $T: X \longrightarrow X$ is a generalized Kannantype contraction mapping and orbitally continuous. Then $T$ has a unique fixed point $z \in X$ and for each $x \in X$, the iterated sequence $\left\{T^{n} x\right\}$ converges to $z$; i.e., $T$ is a Picard operator.

Proof. The proof is analogous.

Remark 1 . Theorems 5 and 6 greatly improve Theorem 2.3 in [6]. The assumptions of compactness and continuity considered in Theorem 2.3 of [6] are relaxed by bounded compactness or $T$-orbital compactness and $T$-orbital continuity, respectively. Corollaries 1 and 2 mainly improve and generalize Theorem 2.2 in [6] and Theorem 2.1 and Theorem 2.2 in [7].

Example 3. Let $\mathscr{A}=\mathbb{R}^{2}$ with the norm $\left\|\left(x_{1}, x_{2}\right)\right\|=\left|x_{1}\right|+\left|x_{2}\right|$. The multiplication is defined by

$$
x y=\left(x_{1}, x_{2}\right)\left(y_{1}, y_{2}\right)=\left(x_{1} y_{1}, x_{1} y_{2}+x_{2} y_{1}\right)
$$

where $x=\left(x_{1}, x_{2}\right), y=\left(y_{1}, y_{2}\right) \in \mathscr{A}$. It follows that $\mathscr{A}$ is a Banach algebra with a unit $e=(1,0)$. Let $P=\left\{\left(x_{1}, x_{2}\right) \in \mathbb{R}^{2}: x_{1}, x_{2} \geq 0\right\}$. Then $P$ is a normal cone with a normal constant $K=1$. Let $X=[-1,2) \cup\{3\} \times[-1,2) \cup\{3\}$ and define the cone $b$-metric $d: X \times X \longrightarrow \mathscr{A}$ by

$$
d\left(\left(x_{1}, x_{2}\right),\left(y_{1}, y_{2}\right)\right)=\left(k_{1}\left|x_{1}-y_{1}\right|^{2}, k_{2}\left|x_{2}-y_{2}\right|^{2}\right) \in P,
$$

for all $x=\left(x_{1}, x_{2}\right), y=\left(y_{1}, y_{2}\right)$ in $X$, where $k_{1}, k_{2}>0$ are constants. Furthermore, define the mapping $T: X \longrightarrow X$ by

$$
T x= \begin{cases}\left(\frac{1}{7} x_{1}, \frac{1}{5} x_{2}\right), & x \neq 3 ; \\ (0,0), & \text { otherwise, }\end{cases}
$$

where $x \neq 3$ is equivalent to $x=\left(x_{1}, x_{2}\right) \neq\left(3, x_{2}\right)$ and $x=\left(x_{1}, x_{2}\right) \neq\left(x_{1}, 3\right)$. Obviously, $T$ is not continuous but $T$-orbitally continuous. Moreover, $(X, d)$ is an incomplete cone $b$-metric space over Banach algebra $\mathscr{A}$ with $s=2$ but $T$-orbitally compact. Let $a_{1}=((4 / 9), 0), a_{2}=$ $((1 / 3), 0), a_{3}=((2 / 9), 0)$, then $a_{1}+a_{2}+a_{3}=e$ and $\left(e-a_{2}\right)^{-1},\left(e-s^{2} a_{3}\right)^{-1}$ exist. In order to check the generalized Reich-Ćirić-Rus-type contraction, we have the following three cases:

(i) If $x \neq 3$ and $y=3$, then

$$
\begin{aligned}
d(T x, T 3) & =\left(k_{1}\left|\frac{1}{7} x_{1}-0\right|^{2}, k_{2}\left|\frac{1}{5} x_{2}-0\right|^{2}\right) \\
& =\left(\frac{1}{49} k_{1} x_{1}^{2}, \frac{1}{25} k_{2} x_{2}^{2}\right) \prec\left(\frac{4}{9}, 0\right)\left(\frac{36}{49} k_{1} x_{1}^{2}, \frac{16}{25} k_{2} x_{2}^{2}\right)+\left(\frac{1}{3}, 0\right)(0,0)+\left(\frac{2}{9}, 0\right)\left(k_{1}\left|x_{1}-2\right|^{2}, k_{2}\left|x_{2}-2\right|^{2}\right) \\
& =\left(\frac{4}{9}, 0\right)\left(k_{1}\left|x_{1}-\frac{1}{7} x_{1}\right|^{2}, k_{2}\left|x_{2}-\frac{1}{5} x_{2}\right|^{2}\right)+\left(\frac{1}{3}, 0\right)(0,0)+\left(\frac{2}{9}, 0\right)\left(k_{1}\left|x_{1}-2\right|^{2}, k_{2}\left|x_{2}-2\right|^{2}\right) \\
& =a_{1} d(x, T x)+a_{2} d(3, T 3)+a_{3} d(x, y) .
\end{aligned}
$$

(ii) If $x, y \in X$ with $x \neq 3, y \neq 3$ and $x \neq y$, then

$$
\begin{aligned}
d(T x, T y)= & \left(k_{1}\left|\frac{1}{7} x_{1}-\frac{1}{7} y_{1}\right|^{2}, k_{2}\left|\frac{1}{5} x_{2}-\frac{1}{5} y_{2}\right|^{2}\right) \\
\prec & \left(\frac{4}{9}, 0\right)\left(\frac{36}{49} k_{1} x_{1}^{2}, \frac{16}{25} k_{2} x_{2}^{2}\right)+\left(\frac{1}{3}, 0\right)\left(\frac{36}{49} k_{1} y_{1}^{2}, \frac{16}{25} k_{2} y_{2}^{2}\right)+\left(\frac{2}{9}, 0\right)\left(k_{1}\left|x_{1}-y_{1}\right|^{2}, k_{2}\left|x_{2}-y_{2}\right|^{2}\right) \\
= & \left(\frac{4}{9}, 0\right)\left(k_{1}\left|x_{1}-\frac{1}{7} x_{1}\right|^{2}, k_{2}\left|x_{2}-\frac{1}{5} x_{2}\right|^{2}\right)+\left(\frac{1}{3}, 0\right)\left(k_{1}\left|y_{1}-\frac{1}{7} y_{1}\right|^{2}, k_{2}\left|y_{2}-\frac{1}{7} y_{2}\right|^{2}\right) \\
& +\left(\frac{2}{9}, 0\right)\left(k_{1}\left|x_{1}-y_{1}\right|^{2}, k_{2}\left|x_{2}-y_{2}\right|^{2}\right)=a_{1} d(x, T x)+a_{2} d(y, T y)+a_{3} d(x, y) .
\end{aligned}
$$


(iii) If $x=3$ and $y=3$, then

$$
\begin{aligned}
d(T x, T y)= & (0,0) \prec a_{1} d(x, T x) \\
& +a_{2} d(y, T y)+a_{3} d(x, y),
\end{aligned}
$$

is clearly true. Therefore, the mapping $T$ has a unique fixed point in $X$ by Theorem 6 .

\section{Asymptotic Regularity and Orbital Completeness}

In the following, we obtain some fixed point theorems of generalized contractive mappings in orbitally complete cone $b$-metric spaces over Banach algebras, under the condition of asymptotic regularity. The regularity or normality of the cone and the continuity of the cone $b$-metric are not necessary. Now, we give the definition of asymptotic regularity, which is a generalization of the counterpart in metric spaces.

Definition 8 (see [27]). Let $(X, d)$ be a metric space. The mapping $T: X \longrightarrow X$ is said to be asymptotically regular, if $\lim _{n \longrightarrow \infty} d\left(T^{n+1} x, T^{n} x\right)=0$ for all $x \in X$.

Definition 9. Let $(X, d)$ be a cone $b$-metric space over a Banach algebra $\mathscr{A}$. The mapping $T: X \longrightarrow X$ is said to be asymptotically regular, if for every $c \in \mathscr{A}$ with $c \gg \theta$, there is a natural number $N$ such that for all $n \geq N, x \in X$, $d\left(T^{n+1} x, T^{n} x\right) \ll c$. That is, $\left\{d\left(T^{n+1} x, T^{n} x\right)\right\}$ is a $c$-sequence for all $x \in X$.

Compared with Definition 8, Definition 9 shows a great generalization. The condition that $\left\{d\left(T^{n+1} x, T^{n} x\right)\right\}$ is a $c$-sequence is a sharp improvement of that $\lim _{n \longrightarrow \infty} d\left(T^{n+1} x, T^{n} x\right)=0$. The latter is established only under normal cones (see Proposition 2.5 in [28]) or usual metric spaces (see $[6,20,21,29]$ ), while the following theorems are established in nonnormal cone $b$-metric space over Banach algebra $\mathscr{A}$. Inspired by the concept of $T$-orbitally complete in metric space [4], we give the similar concept in cone $b$-metric space over a Banach algebra $\mathscr{A}$ as follows.

Definition 10. Let $(X, d)$ be a cone $b$-metric space over a Banach algebra $\mathscr{A}$. The space $(X, d)$ is said to be $T$-orbitally complete, if every Cauchy sequence which is contained in $O_{T}(x)$ for some $x \in X$ converges in $X$. Every complete cone $b$-metric space over Banach algebra $\mathscr{A}$ is $T$-orbitally complete for any $T$, but a $T$-orbitally complete cone $b$-metric space over Banach algebra $\mathscr{A}$ needs not be complete.

The continuity of the mapping and the cone $b$-metric is not necessary in the following theorems.

Theorem 7. Let $T: X \longrightarrow X$ be an asymptotically regular mapping in the T-orbitally complete cone b-metric space over Banach algebra $\mathscr{A}$ with $a$ unit $e$ and the coefficient $s \geq 1$. If there exist $a_{1}, a_{2}, a_{3} \in P$ with $r\left(a_{2}\right)<(1 / s)$ and $r\left(a_{3}\right)<\left(1 / s^{2}\right)$ such that

$$
d(T x, T y) \preccurlyeq a_{1} d(x, T x)+a_{2} d(y, T y)+a_{3} d(x, y),
$$

for all $x, y \in X$, then $T$ has a unique fixed point $z \in X$ and, for each $x \in X$, the iterated sequence $\left\{T^{n} x\right\}$ converges to $z$; i.e., $T$ is a Picard operator.

Proof. For an arbitrary $x_{0} \in X$, let $x_{n}=T x_{n-1}=T^{n} x_{0}, n \geq 1$. Without loss of generality, we assume that $x_{n} \neq x_{n+1}, \forall n \in \mathbb{N}$. Indeed, if for some $n \in \mathbb{N}, x_{n}=x_{n+1}=T x_{n}$, then $x_{n}$ is the fixed point of $T$. By asymptotic regularity of $T,\left\{d\left(x_{n}, x_{n+1}\right)\right\}$ is a $c$-sequence. For all $m>n$, we have

$$
\begin{aligned}
d\left(x_{n}, x_{m}\right) & \leqslant s\left[d\left(x_{n}, x_{n+1}\right)+d\left(x_{n+1}, x_{m}\right)\right] \\
& \leqslant s d\left(x_{n}, x_{n+1}\right)+s^{2} d\left(x_{n+1}, x_{m+1}\right)+s^{2} d\left(x_{m+1}, x_{m}\right) \\
& \leqslant s d\left(x_{n}, x_{n+1}\right)+s^{2}\left[a_{1} d\left(x_{n}, x_{n+1}\right)+a_{2} d\left(x_{m}, x_{m+1}\right)+a_{3} d\left(x_{n}, x_{m}\right)\right]+s^{2} d\left(x_{m+1}, x_{m}\right) \\
& \leqslant s d\left(x_{n}, x_{n+1}\right)+s^{2}\left[a_{1} d\left(x_{n}, x_{n+1}\right)+a_{2} d\left(x_{m}, x_{m+1}\right)+a_{3} d\left(x_{n}, x_{m}\right)\right]+s^{2} d\left(x_{m+1}, x_{m}\right) .
\end{aligned}
$$

Now, $\left(e-s^{2} a_{3}\right)$ is invertible, which is due to the fact that $r\left(s^{2} a_{3}\right)=s^{2} r\left(a_{3}\right)<1$. It follows that

$$
\begin{aligned}
d\left(x_{n}, x_{m}\right) \preccurlyeq & \left(e-s^{2} a_{3}\right)^{-1}\left[\left(s e+s^{2} a_{1}\right) d\left(x_{n}, x_{n+1}\right)\right. \\
& \left.+\left(s^{2} e+s^{2} a_{2}\right) d\left(x_{m}, x_{m+1}\right)\right] .
\end{aligned}
$$

By Lemma $1,\left\{x_{n}\right\}$ is a Cauchy sequence in $X$. Since $(X, d)$ is $T$-orbitally complete, there exists $z \in X$ such that $x_{n} \longrightarrow z$ as $n \longrightarrow \infty$. We shall prove $T z=z$; i.e., $z$ is the fixed point of $T$. By the inequality (34), we have

$$
\begin{aligned}
d(z, T z) & \leqslant s\left[d\left(z, T x_{n}\right)+d\left(T x_{n}, T z\right)\right] \\
& \leqslant s\left[d\left(z, T x_{n}\right)+a_{1} d\left(x_{n}, T x_{n}\right)+a_{2} d(z, T z)+a_{3} d\left(x_{n}, z\right)\right],
\end{aligned}
$$

which implies that 


$$
\begin{aligned}
d(z, T z) \leqslant & \left(e-s a_{2}\right)^{-1} s\left[d\left(z, x_{n+1}\right)\right. \\
& \left.+a_{1} d\left(x_{n}, x_{n+1}\right)+a_{3} d\left(x_{n}, z\right)\right] .
\end{aligned}
$$

The right side of the above equality is a $c$-sequence by Lemma 1, so $z=T z$. Using a similar analysis to Theorem 5, we can prove that $z$ is unique.

Corollary 3. Let $T: X \longrightarrow X$ be an asymptotically regular mapping on the T-orbitally complete cone b-metric space over Banach algebra $\mathscr{A}$ with a unit e and the coefficient $s \geq 1$. If there exists $a \in P$ with $r(a)<\left(1 / s^{2}\right)$ such that

$$
d(T x, T y) \leqslant a[d(x, T x)+d(y, T y)+d(x, y)],
$$

for all $x, y \in X$, then $T$ has a unique fixed point $z \in X$ and for each $x \in X$ the iterated sequence $\left\{T^{n} x\right\}$ converges to $z$; i.e., $T$ is a Picard operator.

Now, if $T$ is orbitally continuous, then the condition $r\left(a_{2}\right)<(1 / s)$ can be deleted.

Theorem 8. Let $T: X \longrightarrow X$ be an asymptotically regular mapping on the $T$-orbitally complete cone $b$-metric space over Banach algebra $\mathscr{A}$ with a unit e and the coefficient $s \geq 1$. There exist $a_{1}, a_{2}, a_{3} \in P$ with $r\left(a_{3}\right)<\left(1 / s^{2}\right)$ such that

$$
d(T x, T y) \preccurlyeq a_{1} d(x, T x)+a_{2} d(y, T y)+a_{3} d(x, y),
$$

for all $x, y \in X$. If $T$ is orbitally continuous, then $T$ has a unique fixed point $z \in X$ and for each $x \in X$ the iterated sequence $\left\{T^{n} x\right\}$ converges to $z$; i.e., $T$ is a Picard operator.

Proof. According to Theorem 7, we see that there exists $z \in X$ such that $x_{n} \longrightarrow z$ as $n \longrightarrow \infty$. Because $T$ is orbitally continuous, we have $x_{n+1}=T x_{n} \longrightarrow T z$ as $n \longrightarrow \infty$. Then, $z=T z$. Similar to Theorem 7 , the conclusion is true.

Corollary 4. Let $T: X \longrightarrow X$ be an asymptotically regular mapping on the T-orbitally complete cone b-metric space over $B$ anach algebra $\mathscr{A}$ with a unite and the coefficient $s \geq 1$. There exist $a, b \in P$ with $r(b)<\left(1 / s^{2}\right)$ such that

$$
d(T x, T y) \leqslant a[d(x, T x)+d(y, T y)]+b d(x, y),
$$

for all $x, y \in X$. If $T$ is orbitally continuous, then $T$ has a unique fixed point $z \in X$ and for each $x \in X$ the iterated sequence $\left\{T^{n} x\right\}$ converges to $z$; i.e., $T$ is a Picard operator.

Remark 2. Corollary 3 is a generalization of Theorems 3.1 and 3.3 in [6]. Similarly, Corollary 4 is an extension of Theorem 2.6 in [20] and Theorem 2.1 in [21], since our cone is a nonnormal cone. In fact, we establish the contractive mappings with several generalized Lipschitz constants, where the constants are all vectors but not usual real constants. These results are not equivalent to the theorems in cone $b$-metric spaces or $b$-metric spaces, which may offer us more applications since there are lots of nonnormal cones (see [23]). Moreover, we weaken the continuity of the mapping which is necessary in Theorem 2.6 of [20] by orbital continuity.

Example 4. Let $\mathscr{A}=C_{\mathbb{R}}^{1}[0,1]$ and $X=[0,1]$. For each $x \in \mathscr{A},\|x\|=\|x\|_{\infty}+\left\|x^{\prime}\right\|_{\infty}$. The multiplication is defined by its usual pointwise multiplication. Then $\mathscr{A}$ is a Banach algebra with a unit $e=1$. Define $d(x, y)(t)=|x-y|^{2} \phi$ for all $x, y \in X$ and $\phi \in P=\{f(t) \in \mathscr{A}: f(t) \geq 0, t \in[0,1]\}$. Then $P$ is a nonnormal cone and $(X, d)$ is a complete cone $b$-metric space over Banach algebra $\mathscr{A}$ with coefficient $s=2$. Choose $\quad a_{1}(t)=4 t+3, a_{2}(t)=5 t+2 \quad$ and $a_{3}(t)=(1 / 9) t+(1 / 9)$. We deduce that

$$
\begin{aligned}
a_{3}^{n}(t) & =\left(\frac{1}{9} t+\frac{1}{9}\right)^{n}, \\
\left(a_{3}^{n}(t)\right)^{\prime} & =\frac{n}{9}\left(\frac{1}{9} t+\frac{1}{9}\right)^{n-1},
\end{aligned}
$$

hence that $(t=1)$

$$
\begin{aligned}
\left\|a_{3}^{n}\right\| & =\left\|a_{3}^{n}\right\|_{\infty}+\left\|\left(a_{3}^{n}\right)^{\prime}\right\|_{\infty}=\left(\frac{2}{9}\right)^{n}+\frac{n}{9}\left(\frac{2}{9}\right)^{n-1} \\
& =\frac{n}{9}\left(\frac{2}{9}\right)^{n-1}\left(\frac{9}{n} \cdot \frac{2}{9}+1\right)=\frac{n}{9}\left(\frac{2}{9}\right)^{n-1}\left(1+\frac{2}{n}\right),
\end{aligned}
$$

and finally that

$r\left(a_{3}\right)=\lim _{n \longrightarrow \infty}\left\|a_{3}^{n}\right\|^{1 / n}=\lim _{n \longrightarrow \infty}\left(\frac{n}{9}\right)^{1 / n}\left(\frac{2}{9}\right)^{(n-1) / n}\left(1+\frac{2}{n}\right)^{1 / n}=\frac{2}{9}$.

This means

$$
r\left(a_{3}\right)=\frac{2}{9}<\frac{1}{4}=\frac{1}{s^{2}} .
$$

Define the mapping $T: X \longrightarrow X$ by

$$
T x= \begin{cases}\frac{x}{10} \sin \frac{x}{9}, & x \in \mathbb{Q} \cap X ; \\ \log \left(1+\frac{x}{4}\right), & x \in(\mathbb{R} \backslash \mathbb{Q}) \cap X .\end{cases}
$$

Then $T$ is asymptotically regular and orbitally continuous but not continuous. Now, we will show that inequality (40) is satisfied in the following three cases: 
(1) For all $x, y \in \mathbb{Q} \cap X$,

$$
\begin{aligned}
d(T x, T y)(t) & =\left|\frac{x}{10} \sin \frac{x}{9}-\frac{y}{10} \sin \frac{y}{9}\right|^{2} \phi \\
& \leqslant\left(\frac{1}{90} x+\frac{1}{10}\right)^{2}|x-y|^{2} \phi \\
& \leqslant(4 t+3)\left|x-\frac{x}{10} \sin \frac{x}{9}\right|^{2} \phi+(5 t+2)\left|y-\log \left(1+\frac{y}{4}\right)\right|^{2} \phi+\left(\frac{1}{9} t+\frac{1}{9}\right)|x-y|^{2} \phi \\
& =a_{1} d(x, T x)(t)+a_{2} d(y, T y)(t)+a_{3} d(x, y)(t) .
\end{aligned}
$$

(2) For all $x, y \in(\mathbb{R} \backslash \mathbb{Q}) \cap X$,

$$
\begin{aligned}
d(T x, T y)(t) & =\left|\log \left(1+\frac{x}{4}\right)-\log \left(1+\frac{y}{4}\right)\right|^{2} \phi \\
& \leqslant\left(\frac{1}{4}\right)^{2}\left|\frac{x}{4}-\frac{y}{4}\right|^{2} \phi \\
& \preccurlyeq(4 t+3)\left|x-\log \left(1+\frac{x}{4}\right)\right|^{2} \phi+(5 t+2)\left|y-\log \left(1+\frac{y}{4}\right)\right|^{2} \phi+\left(\frac{1}{9} t+\frac{1}{9}\right)|x-y|^{2} \phi \\
& =a_{1} d(x, T x)(t)+a_{2} d(y, T y)(t)+a_{3} d(x, y)(t) .
\end{aligned}
$$

(3) For all $x \in \mathbb{Q} \cap X, y \in(\mathbb{R} \mid \mathbb{Q}) \cap X$,

$$
\begin{aligned}
d(T x, T y)(t) & =\left|\frac{x}{10} \sin \frac{x}{9}-\log \left(1+\frac{y}{4}\right)\right|^{2} \phi \\
& \leqslant\left|\frac{x}{10} \sin \frac{x}{9}\right|^{2} \phi+\left|\log \left(1+\frac{y}{4}\right)\right|^{2} \phi \\
& \leqslant\left|\frac{x}{10}\right|^{2} \phi+\left|\frac{y}{4}\right|^{2} \phi \\
& \preccurlyeq(4 t+3)\left|x-\frac{x}{10} \sin \frac{x}{9}\right|^{2} \phi+(5 t+2)\left|y-\log \left(1+\frac{y}{4}\right)\right|^{2} \phi+\left(\frac{1}{9} t+\frac{1}{9}\right)|x-y|^{2} \phi \\
& =a_{1} d(x, T x)(t)+a_{2} d(y, T y)(t)+a_{3} d(x, y)(t) .
\end{aligned}
$$

Similarly, we can also prove that $d(T x, T y)(t) \leqslant$ $a_{1} d(x, T x)(t)+a_{2} d(y, T y)(t)+a_{3} d(x, y)(t)$ for all $x \in(\mathbb{R} \backslash \mathbb{Q}) \cap X, y \in \mathbb{Q} \cap X$. Therefore, $T$ has a unique fixed point in $X$ by Theorem 8 .

\section{Completeness and Fixed Point}

By Corollaries 1 and 2, we know that if the generalized Kannan-type contraction mapping $T$ is orbitally continuous in boundedly compact or T-orbitally compact cone $b$-metric spaces over Banach algebras, then $T$ has a unique fixed point. Conversely, if $T$ has a unique fixed point in cone $b$-metric spaces over Banach algebras, then what conditions do $(X, d)$ have to satisfy? Now, we prove an important theorem showing that the completeness of cone $b$-metric spaces over Banach algebras is necessary if the generalized Kannan-type contraction has a fixed point in $X$. 
Theorem 9. Let $(X, d)$ be a cone b-metric space over Banach algebra $\mathscr{A}$ with a unit $e$ and the coefficient $s \geq 1$. Let $P$ be a normal and strongly minihedral cone. If every self-mapping $T$ satisfying

$$
d(T x, T y) \prec \frac{e}{2}\{d(x, T x)+d(y, T y)\},
$$

for all $x, y \in X$ with $x \neq y$ has a unique fixed point, then $(X, d)$ must be a complete cone b-metric space over Banach algebra $\mathscr{A}$.

Proof. On the contrary, suppose that $(X, d)$ is not complete; then, there exists a Cauchy sequence $\left\{x_{n}\right\}$ in $X$, which is not convergent. If it has a convergent subsequence $\left\{x_{n_{k}}\right\}$ of $\left\{x_{n}\right\}$ such that $x_{n_{k}} \longrightarrow z \in X$ as $k \longrightarrow \infty$, then

$$
d\left(x_{m}, z\right) \leqslant s\left[d\left(x_{m}, x_{n_{k}}\right)+d\left(x_{n_{k}}, z\right)\right],
$$

for all $m \geq n_{k}$. This is a $c$-sequence since $\left\{d\left(x_{m}, x_{n_{k}}\right)\right\}$ and $\left\{d\left(x_{n_{k}}, z\right)\right\}$ are $c$-sequences. Thus, we can assume that all terms of the sequence $\left\{x_{n}\right\}$ are distinct. Let $M=\left\{x_{n}: n \in \mathbb{N}\right\}$; then, $d(x, M)>\theta$ for all $x \in X-M$ by the fact that the sequence $\left\{x_{n}\right\}$ does not converge in $X$. Let $x \in X$ be an arbitrary point. If $x \in X-M$, then there is an integer $n_{x} \in \mathbb{N}$ such that

$$
d\left(x_{m}, x_{n_{x}}\right) \prec \frac{e}{2} d(x, M) \preccurlyeq \frac{e}{2} d\left(x, x_{n}\right),
$$

for all $m \geq n_{x}$ and arbitrary $n \in \mathbb{N}$. That is

$$
d\left(x_{m}, x_{n_{x}}\right) \prec \frac{e}{2} d\left(x, x_{n}\right), \quad \forall m \geq n_{x} \text { and } \forall n \in \mathbb{N} .
$$

Suppose $x^{\prime} \in M$; then $x^{\prime}=x_{n_{0}}$ for some $n_{0} \in \mathbb{N}$. Since $\left\{x_{n}\right\}$ is a Cauchy sequence, we can find some $n_{0}^{\prime} \in \mathbb{N}$ such that

$$
d\left(x_{m}, x_{n_{0}^{\prime}}\right) \prec \frac{e}{2} d\left(x_{n_{0}^{\prime}}, x_{n_{0}}\right), \quad \forall m \geq n_{0}^{\prime}>n_{0} .
$$

Now, define $T: X \longrightarrow X$ by

$$
T x= \begin{cases}x_{n_{x}}, & \text { if } x \in X-M \\ x_{n_{0}^{\prime}}, & \text { if } x \in M \text { and } x=x_{n_{0}} .\end{cases}
$$

For any $x, y \in X$ with $x \neq y$, we divide the following proof into three cases.

Case 1. If $x, y \in X-M$, then $T x=x_{n_{x}}$ and $T y=x_{n_{y}}$. Without loss of generality, we assume that $n_{y} \geq n_{x}$. By (53), we get

$$
d(T x, T y)=d\left(x_{n_{x}}, x_{n_{y}}\right) \prec \frac{e}{2} d\left(x, x_{n_{x}}\right)=\frac{e}{2} d(x, T x) .
$$

This gives $d(T x, T y)<(e / 2)\{d(x, T x)+d(y, T y)\}$.

Case 2. If $x, y \in M$, then $x=x_{n_{0}}$ and $y=x_{m_{0}}$ for some $n_{0}, m_{0} \in \mathbb{N}$. Then $T x=x_{n_{0}^{\prime}}$ and $T y=x_{m_{0}^{\prime}}$. Without loss of generality, we assume that $m_{0}^{\prime} \geq n_{0}^{\prime}$. By (54), we deduce that

$$
d(T x, T y)=d\left(x_{m_{0}^{\prime}}, x_{n_{0}^{\prime}}\right) \prec \frac{e}{2} d\left(x_{n_{0}^{\prime}}, x_{n_{0}}\right)=\frac{e}{2} d(T x, x),
$$

which established the formula $d(T x, T y) \prec(e / 2)$ $\{d(x, T x)+d(y, T y)\}$.

Case 3. If $x \in X-M, y \in M$, then $y=x_{n_{0}}$ for some $n_{0} \in \mathbb{N}$. Therefore $T x=x_{n_{x}}$ and $T y=x_{n_{0}^{\prime}}$. If $n_{0}^{\prime} \geq n_{x}$, by (53), we have $d(T x, T y)=d\left(x_{n_{x}}, x_{n_{0}^{\prime}}\right)=d\left(x_{n_{0}^{\prime}}, x_{n_{x}}\right) \prec \frac{e}{2} d\left(x, x_{n_{x}}\right)=\frac{e}{2} d(x, T x)$,

which yields $d(T x, T y) \leq(e / 2)\{d(x, T x)+d(y, T y)\}$. If $n_{x} \geq n_{0}^{\prime}$, by (54), we see that

$$
d(T x, T y)=d\left(x_{n_{x}}, x_{n_{0}^{\prime}}\right) \prec \frac{e}{2} d\left(x_{n_{0}^{\prime}}, x_{n_{0}}\right)=\frac{e}{2} d(y, T y),
$$

which also gives $d(T x, T y) \prec(e / 2)\{d(x, T x)+d(y, T y)\}$. Therefore, for all $x, y \in X$ with $x \neq y$, we always have $d(T x, T y) \prec(e / 2)\{d(x, T x)+d(y, T y)\}$. That is, $T$ is a generalized Kannan-type contraction mapping which has no fixed point in $X$, a contradiction. Hence, the assumption does not hold and the space $(X, d)$ must be a complete cone $b$-metric space over Banach algebra $\mathscr{A}$. The conclusion is true.

Remark 3. According to the proof of Theorem 9, we see at once that inequality (50) can be replaced by

$$
d(T x, T y) \preccurlyeq k\{d(x, T x)+d(y, T y)\}
$$

for all $x, y \in X$ and a fixed point $k \in P$.

\section{Data Availability}

No data were used to support this study.

\section{Conflicts of Interest}

The authors declare that they have no conflicts of interest.

\section{Acknowledgments}

This research was partially supported by the Undergraduate Teaching Quality Project of Guangdong Province (no. 520006) and the Basic Education Research Project of Hanshan Normal University in 2018 (no. ZD 201807).

\section{References}

[1] S. Banach, "Sur les opérations dans les ensembles abstraits et leur application aux équations intégrales," Fundamenta Mathematicae, vol. 3, no. 1, pp. 133-181, 1922.

[2] R. Kannan, "Some results on fixed points," Bulletin of the Calcutta Mathematical Society, vol. 60, pp. 71-76, 1968.

[3] S. Reich, "Some remarks concerning contraction mappings," Canadian Mathematical Bulletin, vol. 14, no. 1, pp. 121-124, 1971. 
[4] L. B. Ćirić, "A generalization of Banach's contraction principle," Proceedings of the American Mathematical Society, vol. 45, no. 2, pp. 267-273, 1974.

[5] I. A. Rus, Principles and Applications of the Fixed Point Theory (In Romanian), Editura Dacia, Clui-Napoca, Romania, 1979.

[6] J. Górnicki, "Fixed point theorems for Kannan type mappings," Journal of Fixed Point Theory and Applications, vol. 19, no. 3, pp. 2145-2152, 2017.

[7] H. Garai, L. K. Dey, and T. Senapati, "On Kannan-type contractive mappings," Numerical Functional Analysis and Optimization, vol. 39, pp. 1-11, 2018.

[8] N. Haokip and N. Goswami, "Some fixed point theorems for generalized Kannan type mappings in b-metric spaces," Proyecciones (Antofagasta), vol. 38, no. 4, pp. 763-782, 2019.

[9] I. Bakhtin, "The contraction mapping principle in almost metric spaces," Functional Analysis and Its Applications, vol. 30, pp. 26-37, 1989.

[10] S. Czerwik, "Contraction mappings in b-metric spaces," Acta Mathematica et Informatica Universitatis Ostraviensis, vol. 1, no. 1, pp. 5-11, 1993.

[11] M. Boriceanu, M. Bota, and A. Petruşel, "Multivalued fractals in b-metric spaces," Central European Journal of Mathematics, vol. 8, no. 2, pp. 367-377, 2010.

[12] N. Hussian and M. H. Shah, "KKM mappings in cone $b$-metric spaces," Computers \& Mathematics with Applications, vol. 62, no. 4, pp. 1677-1684, 2011.

[13] L.-G. Huang and X. Zhang, "Cone metric spaces and fixed point theorems of contractive mappings," Journal of Mathematical Analysis and Applications, vol. 332, no. 2, pp. 1468-1476, 2007.

[14] P. Kumar and Z. K. Ansari, "Some common fixed point theorems of contractive mappings in cone $b$-metric spaces," International Journal of Machine Intelligence and Applications, vol. 5, no. 4, pp. 1-8, 2017.

[15] H. Liu and S. Xu, "Cone metric spaces with Banach algebras and fixed point theorems of generalized Lipschitz mappings," Fixed Point Theory and Applications, vol. 320, no. 320, pp. 1-10, 2013.

[16] H. Huang and S. Radenović, "Some fixed point results of generalized Lipschitz mappings on cone $b$-metric spaces over Banach algebras," Journal of Computational Analysis and Applications, vol. 20, no. 1, pp. 566-583, 2016.

[17] S. K. Malhotra, J. B. Sharma, and S. Shukla, "Fixed points of $\alpha$-admissible mappings in cone metric spaces with Banach algebra," International Journal of Analysis and Applications, vol. 9, no. 1, pp. 9-18, 2015.

[18] S. Xu, B. Z. Popović, and S. Radenović, "Fixed point results for generalized $g$-quasi-contractions of Perov-type in cone metric spaces over Banach algebras without the assumption of normality," Journal of Computational Analysis and Applications, vol. 22, no. 1, pp. 648-671, 2017.

[19] Y. Han and S. Xu, "Some new theorems on c-distance without continuity in cone metric spaces over Banach algebras," Journal of Function Spaces, vol. 2018, Article ID 7463435, 10 pages, 2018.

[20] J. Górnicki, "Remarks on asymptotic regularity and fixed points," Journal of Fixed Point Theory and Applications, vol. 21, no. 29, pp. 1-20, 2019.

[21] R. K. Bisht, "A note on the fixed point theorem of Górnicki," Journal of Fixed Point Theory and Applications, vol. 21, no. 54, pp. 1-3, 2019.

[22] W. Rudin, Functional Analysis, McGraw-Hill, New York, NY, USA, 2nd edition, 1991.
[23] S. Rezapour and R. Hamlbarani, "Some notes on the paper "Cone metric spaces and fixed point theorems of contractive mappings"," Journal of Mathematical Analysis and Applications, vol. 345, no. 2, pp. 719-724, 2008.

[24] A. Sönmez, "On paracompactness in cone metric spaces," Applied Mathematics Letters, vol. 23, no. 4, pp. 484-497, 2010.

[25] K. P. Chi and T. V. An, "Dugundji's theorem for cone metric spaces," Applied Mathematics Letters, vol. 24, no. 3, pp. 387-390, 2011.

[26] Z. Kadelburg and S. Radenovic, "A note on various types of cones and fixed point results in cone metric spaces," Asian Journal of Mathematics and Applications, vol. 2013, pp. 1-7, 2013.

[27] F. E. Browder and W. V. Peryshyn, "The solution by iteration of nonlinear functional equations in Banach spaces," American Mathematical Society, Bulletin, vol. 72, no. 3, pp. 571-575, 1966.

[28] H. Huang, G. Deng, and S. Radenović, "Some topological properties and fixed point results in cone metric spaces over Banach algebras," Positivity, vol. 23, pp. 21-34, 2019.

[29] J. Górnicki, "Various extensions of Kannan's fixed point theorem," Journal of Fixed Point Theory and Applications, vol. 20, no. 20, pp. 1-12, 2018. 